the same angle with a pupillary distance of $54 \mathrm{~mm}$. a stereoscopic radius of $360 \mathrm{~mm}$.

This way of measuring the power of stereoscopic vision would not only have the advantage of paying due influence to the pupillary distance, but seems also to give a more expressive and tangible evaluation of the same. It seems therefore desirable that an exchange of the angle of distinction against the radius should be considered in the future discussion of the internationalisation of this measure.

\title{
A CASE OF SPONTANEOUS EXOPHTHALMOS DURING DELIVERY*
}

BY

\section{J. GOLDBERG \\ EDINBURGH}

A CASE of unilateral exophthalmos occurring during delivery was seen by me, and because reference to this condition in the literature is scarce, I think it of sufficient interest to put on record.

The patient, a 32 years old woman, had previously been healthy. Her blood pressure was $120 / 80$, urine normal, Wassermann reaction of blood-negative. This was her first pregnancy and it was uneventful up to the time of delivery. Three weeks before the expected time, she started to bleed, and was sent to the hospital for induction of labour. During one of her severe pains of the second stage of labour, she suddenly complained of dimness of vision of the left eye, and protrusion of the eye was noticed. I was asked to see this patient shortly after delivery, and found the right eye completely normal. The left eye was considerably proptosed, the upper lid oedematous and the lower lid tucked away behind the proptosed eye. The cornea and conjunctiva were normal, the pupil widely and irregularly dilated without direct reaction to light and the eyeball was completely fixed. The fundus showed gross retinal oedema but details were not discernable. The eye was blind.

Two days later there was some return of movement, the upper lid showed suffusion, but no subconjunctival haemorrhages were present. The fundus was now covered with haemorrhages particularly in the macular region and the disc was pale. During the next ten days the eye movement improved in all directions except upward, the proptosis receded and the retinal haemorrhages

* Received for publication, July 16, 1948. 
partially disappeared." There was some brownish discolouration of the subconjunctival tissues at the upper part of the sclera. Suddenly the proptosis increased again, the upper lid became more swollen and local pain indicated a beginning of inflammatory reaction. No elevated temperature. This subsided with penicillin and sulphadiazine. When I saw her last (about three months after the first examination) there was no exophthalmos, but optic atrophy and pigmentary and degenerative changes in the macula. The eye was blind. The explanation seems to me, a spontaneous orbital haemorrhage which produced an arterial occlusion and venous thrombosis.

I wish to thank Dr. Traquair for the help he has given me in reporting this case.

\section{REFERENCE}

Вӧнм.-Ein Fall von spontaneur Exophthalmus wahrand der Geburt. Die ophthal. Klinik III. S. 3-5, 1899.

\section{ANNOTATION}

\section{Medical False Quantities}

At first sight our title might seem to indicate errors on the dispensing of medicines, but we may as well confess that our reflections this month are devoted to the false pronunciation of classical words. It is a matter on which the writer can speak with some authority, for if there is a chance of making a false quantity he can be relied upon to make it nine times out of ten.

To be candid, he resembles Macaulay's friend who never knew the difference between an aphorism and an apophthegm, and could be relied upon to make a dozen false quantities in as many lines of print.

Medical terms offer almost unlimited scope for the habit. Perhaps the one most usually made by every one is the shin bone. Even doctors who are classical scholars talk about a fractured tibia. But if you turn to the VIIIth Eclogue of Virgil you find that the word is a dactyl and that the first " $i$ " is long. Angina, with the " $i$ " long, is another false quantity that has come into common parlance. In classical verse it is "angina" with a short " $i$ ". The late Mr. Herbert Fisher once told the writer of an occasion on which he harrowed the soul of a famous schoolmaster by making a false quantity in speaking of the pituitary gland. Had he done this as a schoolboy the results might have been even more distressing than they were. After all, what does it matter? In dealing with 